\title{
Trans-scapular approach coil localization for scapular-blocked pulmonary nodules: a retrospective study
}

\author{
Juan Wu, Min-Ge Zhang, Jin Chen and Wen-Bin Ji*
}

\begin{abstract}
Background: Preoperative computed tomography (CT)-guided coil localization (CL) is commonly used to facilitate video-assisted thoracoscopic surgery (VATS)-guided diagnostic wedge resection (WR) of pulmonary nodules (PNs). When a scapular-blocked PN (SBPN) is localized, the trans-scapular CL (TSCL) is commonly performed. In this study, we investigated the safety, feasibility, and clinical efficacy of preoperative CT-guided TSCL for SBPNs.

Materials and methods: From January 2014 to September 2020, a total of 152 patients with PNs underwent CTguided CL prior to VATS-guided WR. Of these patients, 14 had SBPNs and underwent the TSCL procedure.

Results: A total of 14 SBPNs were localized in the 14 patients. The mean diameter of the 14 SBPNs was $7.4 \pm 2.4$ $\mathrm{mm}$. The technical success rate of the scapula puncture was $100 \%$. No complications occurred near the scapula. The technical success rate of $\mathrm{CL}$ was $92.9 \%$. One coil dropped off when performing the VATS procedure. The mean duration of the TSCL was $14.2 \pm 2.7 \mathrm{~min}$. Two patients (14.3\%) developed asymptomatic pneumothorax after TSCL. The technical success rate of VATS-guided WR was $92.9 \%$. The patient who experienced technical failure of TSCL directly underwent lobectomy. The mean duration of the VATS was $90.0 \pm 42.4 \mathrm{~min}$ and the mean blood loss was $62.9 \pm 37.2 \mathrm{ml}$. The final diagnoses of the 14 SBPNs included invasive adenocarcinoma $(n=4)$, adenocarcinoma in situ $(n=9)$, and benign disease $(n=1)$.
\end{abstract}

Conclusions: Preoperative CT-guided TSCL is a safe and simple procedure that can facilitate high success rates of VATS-guided WR of SBPNs.

Keywords: Computed tomography, Scapular, Coil, Pulmonary nodule

\section{Background}

Pulmonary nodules (PNs) are commonly detected in the clinic by chest computed tomography (CT) [1-5]. Although most of PNs can be regularly followed up by CT according to the Fleischner Society or Lung-RADS guidelines [6, 7], many intermediate or high risk PNs should be managed actively. Currently, lung biopsy or video-assisted thoracoscopic surgery (VATS)-guided diagnostic wedge resection (WR) are widely used to

\footnotetext{
* Correspondence: jiwenbin2016@163.com

Department of Radiology, Taizhou Hospital of Zhejiang Province affiliated to Wenzhou Medical University, Taizhou, China
}

diagnose the PNs [8-10]. Although lung biopsy is a minimally invasive procedure that requires only local anaesthesia, it is associated with a diagnostic failure rate of around $10 \%$ [11].

Preoperative CT-guided localization is commonly used to facilitate the VATS-guided diagnostic WR of PNs as it decreases the need for thoracotomy or VATS anatomic resection for the diagnosis of PNs $[8,12]$. Localized materials usually include coils, hook-wire, methylene blue, and radio-labeling agents [8]. The process of coil localization $(\mathrm{CL})$ typically has the lowest rate of complications [8]. 
Although most of the PNs can be easily detected with a needle pathway to perform the biopsy or localization, some PNs can be blocked by the scapula [13, 14]. Under the typical conditions, the scapula can be punctured when performing the lung interventions for the scapulablocked lung lesions [13, 14]. However, few studies have reported on trans-scapular CL (TSCL) for scapularblocked PNs (SBPNs).

In this study, we aimed to investigate the safety, feasibility, and clinical efficacy of preoperative CT-guided TSCL for SBPNs.

\section{Methods}

This retrospective, single-center study was approved by our Institutional Review Board and did not require written informed.

\section{Study design}

From January 2014 to September 2020, a total of 152 patients with PNs underwent CT-guided CL prior to VATS-guided WR. Of these patients, 14 patients (9.2\%) had SBPNs and underwent the TSCL procedure.
The inclusion criteria were as follows: (a) a definite SBPN detected on CT; (b) PNs with a diameter $\leq 3 \mathrm{~cm}$ (sub-solid PNs $\leq 30 \mathrm{~mm}$; solid PNs $\leq 15 \mathrm{~mm}$ ); (c) the PNpleura distance $\leq 20 \mathrm{~mm}$; and (d) PNs lacking a definite pathological diagnosis.

The exclusion criteria were as follows: (a) a PN diameter $<5 \mathrm{~mm}$; (b) a PN which decreased in size during CT follow-up; and (c) any abnormal coagulation activity, active bleeding, active infections, or limited cardiopulmonary reserve.

\section{Puncture of the scapula}

All procedures were performed by an interventional radiologist with more than 5 years of experience conducting CT-guided interventions using a 64-row CT (GE Healthcare, Milwaukee, WI). Patients were placed in the prone position and were administered local anesthesia.

A preoperative $\mathrm{CT}$ scan was used to ensure the needle pathway (Fig. 1a). A 17G needle (DuoSmart, Modena, Italy) was used to puncture the scapula. When the needle contacted the scapula, it was punctured using a drill and inserted under steady pressure. A repeat CT scan
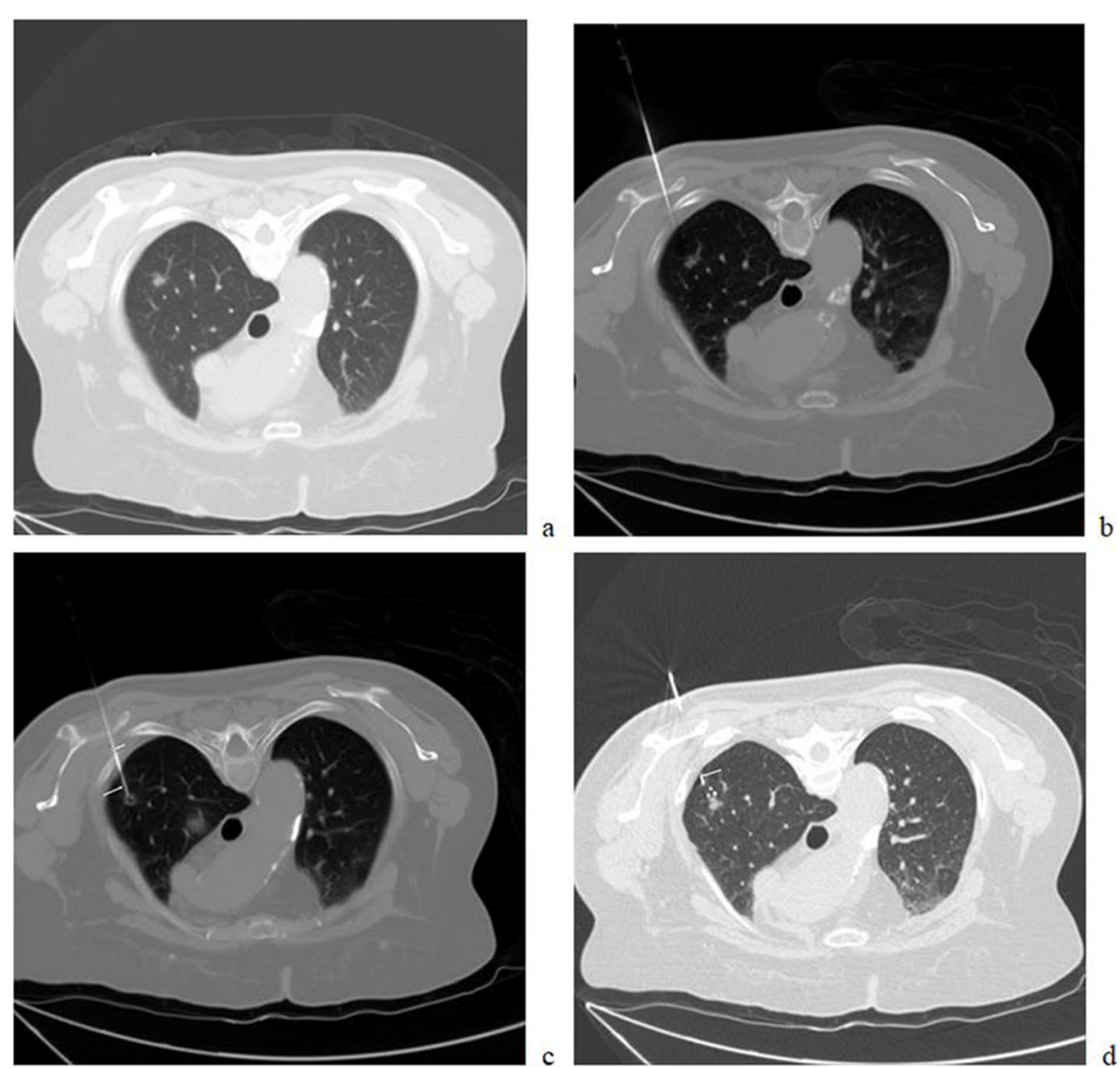

Fig. 1 (a) Preoperative CT indicating a SBPN located at the right upper lobe; (b) A 17G needle was used to puncture the scapular; (c) An 18G needle (long arrow) was inserted into the lung for coil localization via the 17G needle (short arrow); (d) The coil tail (arrow) remained above the visceral pleura 
was performed to observe the location of the needle tip and any procedure-related complications (Fig. 1b). When the $17 \mathrm{G}$ needle was passed across the scapula, the needle tip was carefully pushed close to the lung, but the needle tip did not enter the lung.

\section{Localization procedure}

When the 17G needle was passed through the scapula, an 18G needle (Precisa, Roma, Italy) was inserted from the $17 \mathrm{G}$ needle and smoothly pushed to the lung to within approximately $10 \mathrm{~mm}$ of the PN (Fig. 1c). Next, a coil (5 $\mathrm{cm}$ long and 0.038 in. in diameter, Cook, Bloomington, IN) was partially placed into the pulmonary parenchyma. The needle was smoothly retracted to ensure that the coil tail remained above the visceral pleura (Fig. 1d). A repeat CT scan was performed to observe the location of the coil and any procedure-related complications.

\section{VATS procedure}

VATS-guided WR was routinely performed within $24 \mathrm{~h}$ of localization. The coil tail was used to guide this procedure. When the coil tail was detected under the thoracoscope, the WR was performed with a cutting margin $>20 \mathrm{~mm}$ from the coil tail. If the coil tail was not visible, the coil was considered to be completely inserted into the pulmonary parenchyma. Palpation of the coil was performed to conduct the WR. If this procedure is unsuccessful, lobectomy should be performed.

The resected lesions were sent for a rapid pathological examination. If the pathological diagnosis indicated a benign lesion, carcinoma in situ, mini-invasive carcinoma, or metastatic PN, the VATS was terminated. In these cases, further lobectomy and lymph node dissection should be performed when the PN is diagnosed as invasive carcinoma.

\section{Definitions}

SBPN was defined as the PN with the lesion-pleura vertical line striding across the scapula. The technical success of TSCL was defined when the coil tail could be detected under the thoracoscope. The technical success of the WR was defined when the PN was found in the resected wedge tissue.

The primary endpoint was the technical success of the TSCL. The secondary endpoints included localizationrelated complications, technical success of VATS-guided WR, and final diagnoses of the PNs.

\section{Statistical analysis}

All statistical analyses were conducted using SPSS 16.0 (SPSS Inc., Chicago, IL). Continuous variables are presented as the mean \pm standard deviation. Categorical data are presented as a percentage (number/total).

\section{Results}

Patients

The baseline data of the 14 patients are summarised in Table 1. Seven females and 7 males were analysed in the study and the patients had a mean age of $57.0 \pm 7.8 \mathrm{y}$. None of the patients had a previous history of cancer.

\section{SBPNs}

The baseline data of the SBPNs are shown in Table 2 . Each patient had 1 SBPN. The mean diameter of the 14 SBPNs was $7.4 \pm 2.4 \mathrm{~mm}$. Eight SBPNs were located in the upper right lobe and 6 were located in the upper left lobes.

The indications for resection of the SBPNs included: (a) high-risk of lung cancer based on the clinicalradiological features $(n=8)$ [1, 6, 7]; and (b) PNs with the increasing size or solid components $(n=6)$.

\section{TSCL procedure}

The technical success rate of puncture of the scapula was $100 \%$ and no complications occurred near the scapula. The technical success rate of CL was $92.9 \%(13 / 14$, Table 3). One coil dropped off when performing the VATS procedure. The mean needle-pleura degree was $80.4 \pm 4.5$ degrees. The mean duration of the TSCL was $14.2 \pm 2.7 \mathrm{~min}$.

Two patient (14.3\%) developed aysmptomatic pneumothorax after TSCL but this did not impact the subsequent VATS procedure.

\section{VATS-guided WR}

The technical success rate of the VATS-guided WR was 92.9\% (13/14, Table 4). The patient who experienced technical failure of the TSCL directly underwent lobectomy. Four patients underwent additional lobectomy after WR due to the pathological diagnosis of invasive adenocarcinoma.

The mean duration of the VATS procedure was $90.0 \pm 42.4 \mathrm{~min}$ and the mean blood loss was $62.9 \pm 37.2$ $\mathrm{ml}$. The final diagnoses of the 14 SBPNs included invasive adenocarcinoma $(n=4)$, adenocarcinoma in situ $(n=9)$, and benign disease $(n=1)$. The pathological diagnosis of the SBPN in the patient who experienced technical failure WR was adenocarcinoma in situ.

Table 1 Baseline data of the 14 patients

\begin{tabular}{ll}
\hline & Values \\
\hline Patients number & 14 \\
Age (y) & $57.0 \pm 7.8$ \\
Gender (male/female) & $7 / 7$ \\
Tumor history & 0 \\
Smoking history & 5 \\
\hline
\end{tabular}


Table 2 Baseline data of the nodules

\begin{tabular}{ll}
\hline & Values \\
\hline Nodules number & 14 \\
Diameter (mm) & $7.4 \pm 2.4$ \\
Natures of nodules & \\
$\quad$ Solid & 6 \\
Sub-solid & 8 \\
$\quad$ Nodule-pleura distance $(\mathrm{mm})$ & $5.6 \pm 5.1$ \\
Side & \\
$\quad$ Left & 6 \\
Right & 8 \\
\hline
\end{tabular}

\section{Discussion}

The present study demonstrated the feasibility, safety, and clinical efficacy of preoperative CT-guided TSCL for SBPNs. During the CT-guided lung interventions, the needle pathway may be blocked by the bone structures $[13,14]$. In most cases, the bone structures should be avoided and an alternative pathway chosen. However, unlike other lung interventions (biopsy or ablation), CTguided CL of PNs requires the coil tail to remain on the pleural surface nearest the PN to ensure the technical success of VATS-guided WR [12]. Thus, the shortest needle pathway is essential to the CT-guided CL procedure even when the optimal pathway is blocked by the bone structures.

In the current study, the scapula was successfully punctured in all patients with a high technical success rate (92.9\%) of CT-guided TSCL. These rates were consistent with technical success rates previously reported in studies of CT-guided trans-bone lung ablation or biopsy (91-100\%) [13-15] and in CT-guided CL for PNs $(90-100 \%)[12,16-18]$. Previous reports of percutaneous needle approaches in the scapular region did not observe neurovascular injury or significant hemorrhage associated with the procedures [13-15]. In this study, no complications were observed near the scapula.

Several previous clinical studies have reported on the application of CT-guided CL for sub-fissural or multiple

Table 3 Details of CT-guided localization

\begin{tabular}{ll}
\hline & Values \\
\hline Technical success of localization & $13(92.9 \%)$ \\
Duration of CT-guided procedure (min) & $14.2 \pm 2.7$ \\
Needle-pleura degree & $80.4 \pm 4.5$ \\
Complications & \\
Haematoma near the scapula & 0 \\
Pneumothorax & $2(14.3 \%)$ \\
Lung haemorrhage & 0 \\
\hline
\end{tabular}

CT computed tomography
Table 4 Details of VATS procedures

\begin{tabular}{ll}
\hline & Values \\
\hline Technical success of WR & $13(92.9 \%)$ \\
Types of surgery & 9 \\
WR & 4 \\
WR + lobectomy & 1 \\
Lobectomy & $90.0 \pm 42.4$ \\
Duration of VATS (min) & $62.9 \pm 37.2$ \\
Blood loss (ml) & \\
Final diagnoses & 4 \\
Invasive adenocarcinoma & 9 \\
Adenocarcinoma in situ & 1 \\
Benign &
\end{tabular}

VATS video-assisted thoracoscopic surgery; WR wedge resection

PNs [18-20]. In comparison to these studies, the CTguided TSCL technique is simpler as it only necessitates puncturing of the scapula and we found that this could be achieved effectively using a $17 \mathrm{G}$ needle. Following the puncture of the scapular, an $18 \mathrm{G}$ needle was coaxially inserted to facilitate coil placement and to reduce the risk of pneumothorax.

In this study, the rate of asymptomatic pneumothorax was $14.3 \%$ which is comparable to that observed in previous studies of CT-guided coil localization (9-40\%) [16-18] and CT-guided trans-scapular lung interventions $(18-29 \%)$ [13-15].

In this study, the technical success rate of VATSguided WR was $92.9 \%$ which is consistent with findings for the majority of preoperative CT-guided CL in other special PNs (95-100\%) [18-20]. Preoperative CT-guided TSCL can achieve a high technical success rate of WR when evaluating SBPNs and also preserve maxim lung function .

Our study had several limitations. The analysis was performed as a retrospective study from a single-center and is subject to selection bias and the sample size was small. However, our study focused on special cases that had SBPNs. Previous studies that have focused on transscapula lung interventions have also analyzed small patient cohorts limited to 5-12 patients [13-15]. Also, no control group was set in this study. When we began to use the preoperative localization for PNs, we always used the CLand had no cases that were localized by other materials. Further randomized controlled trials are needed to validate our findings.

\section{Conclusions}

Preoperative CT-guided TSCL can be safely and simply used to facilitate high success rates of VATS-guided WR of SBPNs. 


\section{Abbreviations}

CT: Computed tomography; CL: Coil localization; PN: Pulmonary nodule; SBPN: Scapular-blocked PN; TSCL: Trans-scapular CL; VATS: Video-assisted thoracoscopic surgery; WR: Wedge resection

\section{Acknowledgments}

None.

\section{Authors' contributions}

WBJ designed this study, MGZ and WBJ performed the CT-guided procedure, JC collected the patients' data; JC and JW analyzed these data; JW wrote and revised this paper; Final manuscript was approved by all authors.

\section{Funding}

None.

\section{Availability of data and materials}

The data that support the findings of this study are available from the corresponding author upon reasonable request.

\section{Declarations}

\section{Ethics approval and consent to participate}

This retrospective study was approved by institutional review board of Taizhou Hospital of Zhejiang Province affiliated to Wenzhou Medical University. The written informed consent was waived due to the retrospective nature. Only the relevant patient provided informed consent for publication of the images in Fig. 1.

\section{Consent for publication}

The relevant patient provided informed consent for publication of the images in Fig. 1.

\section{Competing interests}

None.

Received: 23 October 2020 Accepted: 18 March 2021

Published online: 25 March 2021

\section{References}

1. van't Westeinde SC, de Koning HJ, Xu DM, Hoogsteden HC, van Klaveren RJ. How to deal with incidentally detected pulmonary nodules less than $10 \mathrm{~mm}$ in size on CT in a healthy person. Lung Cancer. 2008;60(2):151-9. https://doi. org/10.1016/j.lungcan.2008.01.020.

2. Winer-Muram HT. The solitary pulmonary nodule. Radiology. 2006;239(1):3449. https://doi.org/10.1148/radiol.2391050343.

3. Xie Y, Zhang J, Xia Y. Semi-supervised adversarial model for benignmalignant lung nodule classification on chest CT. Med Image Anal. 2019;57: 237-48. https://doi.org/10.1016/j.media.2019.07.004.

4. Zhang Y, Shen Y, Qiang JW, Ye JD, Zhang J, Zhao RY. HRCT features distinguishing pre-invasive from invasive pulmonary adenocarcinomas appearing as ground-glass nodules. Eur Radiol. 2016;26(9):2921-8. https:// doi.org/10.1007/s00330-015-4131-3.

5. Zhang Y, Qiang JW, Ye JD, Ye XD, Zhang J. High resolution CT in differentiating minimally invasive component in early lung adenocarcinoma. Lung Cancer. 2014;84(3):236-41. https://doi.org/10.1016/j.lungcan.2014.02. 008.

6. MacMahon H, Naidich DP, Goo JM, Lee KS, Leung ANC, Mayo JR, et al. Guidelines for Management of Incidental Pulmonary Nodules Detected on CT images: from the Fleischner society. Radiology. 2017;2017:284228-43.

7. Godoy MCB, Odisio EGLC, Truong MT, de Groot PM, Shroff GS, Erasmus JJ. Pulmonary nodule Management in Lung Cancer Screening: a pictorial review of lung-RADS version 1.0. Radiol Clin N Am. 2018;56(3):353-63. https://doi.org/10.1016/j.rcl.2018.01.003.

8. Park CH, Han K, Hur J, Lee SM, Lee JW, Hwang SH, et al. Comparative effectiveness and safety of preoperative lung localization for pulmonary nodules: a systematic review and meta-analysis. Chest. 2017;151(2):316-28. https://doi.org/10.1016/j.chest.2016.09.017

9. Li Y, Wang T, Fu YF, Shi YB, Wang JY. Computed tomography-guided biopsy for sub-centimetre lung nodules: technical success and diagnostic accuracy. Clin Respir J. 2020;14(7):605-10. https://doi.org/10.1111/crj.13172.
10. Fu YF, Li GC, Xu QS, Shi YB, Wang C, Wang T. Computed tomographyguided lung biopsy: a randomized controlled trial of low-dose versus standard-dose protocol. Eur Radiol. 2020;30(3):1584-92. https://doi.org/10.1 007/s00330-019-06464-6.

11. Liu GS, Wang SQ, Liu HL, Liu Y, Fu YF, Shi YB. Computed tomographyguided biopsy for small ( $\leq 20 \mathrm{~mm}$ ) lung nodules: a meta-analysis. J Comput Assist Tomogr. 2020;44(6):841-6. https://doi.org/10.1097/RCT.0000000000001 071. Epub ahead of print. PMID: 32976266.

12. Finley RJ, Mayo JR, Grant K, Clifton JC, English J, Leo J, et al. Preoperative computed tomography-guided microcoil localization of small peripheral pulmonary nodules: a prospective randomized controlled trial. J Thorac Cardiovasc Surg. 2015;149(1):26-31. https://doi.org/10.1016/j.jtcvs.2014.08. 055.

13. Rossi UG, Seitun S, Ferro C. MDCT-guided transthoracic needle aspiration biopsy of the lung using the transscapular approach. Cardiovasc Intervent Radiol. 2011;34(1):184-7. https://doi.org/10.1007/s00270-010-9816-Z.

14. Rebonato A, Maiettini D, Andolfi M, Fischer MJ, Vannucci J, Metro G, et al. CT-guided percutaneous trans-scapular lung biopsy in the diagnosis of peripheral pulmonary lesion nodules of the superior lobes using large needles. Cardiovasc Intervent Radiol. 2018;41(2):284-90. https://doi.org/10.1 007/s00270-017-1768-0.

15. Iguchi T, Hiraki T, Ishii H, Gobara H, Fujiwara $H$, Matsui $Y$, et al. Transosseous route for CT fluoroscopy-guided radiofrequency ablation of lung tumors. J Vasc Interv Radiol. 2015;26(11):1694-8. https://doi.org/10.1016/j.jvir.2015.08. 012.

16. Fu YF, Zhang M, Wu WB, Wang T. Coil localization-guided video-assisted thoracoscopic surgery for lung nodules. J Laparoendosc Adv Surg Tech A. 2018;28(3):292-7. https://doi.org/10.1089/lap.2017.0484

17. Su TH, Fan YF, Jin L, He W, Hu LB. CT-guided localization of small pulmonary nodules using adjacent microcoil implantation prior to videoassisted thoracoscopic surgical resection. Eur Radiol. 2015;25(9):2627-33. https://doi.org/10.1007/s00330-015-3676-5.

18. Xia FF, Shi YB, Wang T, Fu YF. Computed tomography-guided Transfissural coil localization of lung nodules. Thorac Cardiovasc Surg. 2020;68:545-8.

19. Fu YF, Gao YG, Zhang M, Wang T, Shi YB, Huang YY. Computed tomography-guided simultaneous coil localization as a bridge to one-stage surgery for multiple lung nodules: a retrospective study. J Cardiothorac Surg. 2019;14:43

20. Teng F, Wu AL, Yang S, Lin J, Xian YT, Fu YF. Preoperative computed tomography-guided coil localization for multiple lung nodules. Ther Adv Respir Dis. 2020;14:1753466620909762.

\section{Publisher's Note}

Springer Nature remains neutral with regard to jurisdictional claims in published maps and institutional affiliations.

Ready to submit your research? Choose BMC and benefit from:

- fast, convenient online submission

- thorough peer review by experienced researchers in your field

- rapid publication on acceptance

- support for research data, including large and complex data types

- gold Open Access which fosters wider collaboration and increased citations

- maximum visibility for your research: over $100 \mathrm{M}$ website views per year

At $\mathrm{BMC}$, research is always in progress.

Learn more biomedcentral.com/submissions 